\title{
Correction to: Demographic and Behavioral Profiles of Nonbinary and Binary Transgender Youth by Todd K, Peitzmeier SM, Kattari SK, Miller-Perusse M, Sharma A, and Stephenson R. Transgender Health 2019;4:254-261. DOI: 10.1089/trgh.2018.0068
}

N THE 2019 ISSUE of Transgender Health (volume 4, number 1, pp. 254-261), the article entitled Demographic and Behavioral Profiles of Nonbinary and Binary Transgender Youth by Todd et al. requires correction.

The name of the fourth author was spelled incorrectly. The author's name was published in this article as:

Michael Miller-Peruse

The author's name should have appeared as:

Michael Miller-Perusse

The online version of the article has been corrected to reflect this change.

The authors apologize for this error.

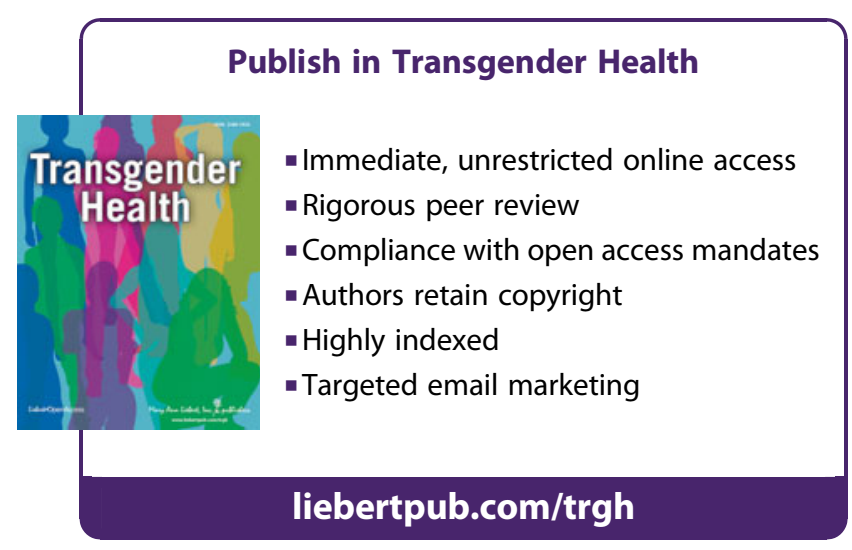

